\title{
Análisis comparativo del impacto al recurso hídrico generado en los principales rellenos sanitarios en Colombia
}

\section{Comparative Analysis of Impacts on Water Resources Generated by Major Landfills in Colombia}

\author{
Diana Lucía Cristancho Montenegro \\ Facultad de Ingeniería y Ciencias Básicas, Departamento de Ingeniería Ambiental, Universidad Central, Colombia \\ https://orcid.org/0000-0001-7417-2583 | inge.dianacristancho26@gmail.com
}

Angie Stefany Torres Mejía

Facultad de Ingeniería y Ciencias Básicas, Departamento de Ingeniería Ambiental, Universidad Central, Colombia https://orcid.org/0000-0002-7083-3679 | atorresm6@ucentral.edu.co

Johan Fernando Lobatón Orduz

Facultad de Ingeniería y Ciencias Básicas, Departamento de Ingeniería Ambiental, Universidad Central, Colombia https://orcid.org/0000-0002-2422-8574 | jlobatono@ucentral.edu.co

Fecha de recepción: 30 de mayo de 2019

Fecha de aprobación: 30 de julio de 2019

Sugerencia de citación: Cristancho -Montenegro, D. L., Torres-Mejía, A. S. y Lobatón- Orduz, J. F. (2020). Análisis comparativo del impacto al recurso hídrico generado en los principales rellenos sanitarios en Colombia. Mutis, 10 (1), 25-45. doi:10.21789/22561498.1601

\section{RESUMEN}

Este trabajo presenta una revisión del estado actual del tratamiento de los lixiviados generados en los rellenos sanitarios (RESA) de Colombia, teniendo en cuenta el impacto ambiental negativo generado como consecuencia del vertimiento de estos compuestos, los cuales afectan directamente a las fuentes hídricas. Se realizó un diagnóstico que evidenció la existencia de 144 RESA en Colombia. Con base en la aplicación de un filtro que contempló las variables cantidad de habitantes, cantidad de toneladas de residuos generados y caudal del lixiviado generado, se determinó que 17 de estos RESA eran aptos como objeto de estudio. De estos, según la normatividad aplicable y las últimas caracterizaciones realizadas por entes de control, todos están por encima de los límites permisibles para el vertimiento de lixiviados, generando impactos negativos en algunos cuerpos de agua; principalmente, por la presencia de contaminantes de alta toxicidad como cadmio, cromo, plomo, bromo, zinc y mercurio, los cuales no pueden ser eliminados de manera natural en las fuentes de 
agua y derivan en bioacumulación y la ocurrencia de catástrofes ambientales. Con base en lo anterior, se compararon los tratamientos con mayor eficiencia para la remoción de este tipo de contaminantes actualmente empleados en Colombia, considerando, además, los parámetros fisicoquímicos de cada uno de los 17 RESA estudiados. Como consecuencia, se determinó que el tratamiento con mejor eficiencia es la osmosis inversa. No obstante, se sugiere la implementación de pretratamientos a lo largo del sistema de los RESA. Así mismo, se determinó que el río Magdalena es el cuerpo de agua de mayor afectación debido a que 5 RESA vierten sus lixiviados en él.

Palabras clave: lixiviado, planta de tratamiento de lixiviados (PTL), osmosis inversa, impacto ambiental, recurso hídrico.

\section{ABSTRACT}

This study reviews the current status in the treatment of leachates generated in sanitary landfills in Colombia, considering the negative environmental impact generated by their discharge on water sources. A diagnosis of sanitary allowed identifying 144 of these sites in Colombian territory. Using a filter of parameters such as number of inhabitants, number of tons of waste generated, and flow of leachates generated, 17 landfills were selected as object of study. According to current regulations and the latest characterizations carried out by control entities, it was found that all these 17 landfills are above the permissible limits for leachates dumping, thus negatively affect some bodies of water with highly toxic pollutants such as cadmium, chromium, lead, bromine, zinc, and mercury, which cannot be eliminated naturally, causing bioaccumulation and environmental catastrophes. Therefore, the most efficient treatments for the removal of this type of pollutants used in Colombia were compared based on the physicochemical parameters of each of the 17 sites studied. As a consequence, reverse osmosis was identified as the treatment with higher efficiency. However, pretreatments are suggested throughout the sanitary landfill system. In addition, it was also determined that the Magdalena River is the most affected body of water in the country, since 5 landfills discharge its leachates in their waters.

Keywords: Leachate, leachate treatment plant (LTP), reverse osmosis, environmental impact, water resources.

\section{INTRODUCCIÓN}

Los niveles de contaminación reportados en Colombia han crecido notablemente durante los últimos años, particularmente en lo que concierne a la afectación de la calidad del agua, la cual manifiesta la presencia de contaminantes de material biodegradable, no biodegradable, nutrientes, metales pesados y mercurio (IDEAM, 2014). Este fenómeno es provocado por diferentes actividades antrópicas.

Sin embargo, la mayor fuente contaminante está dada por las grandes descargas de lixiviados que generan diariamente los rellenos sanitarios (en adelante RESA), situación que amenaza la sostenibilidad del recurso hídrico y pone en riesgo la salud de la población. Según información del Ministerio de Ambiente y Desarrollo Sostenible (MADS), "los lixiviados son líquidos altamente contaminados, producto de la perco- lación de agua a través de los residuos en proceso de degradación" (Decreto 1713 de 2002).

En consecuencia, el vertimiento de lixiviados genera grandes impactos, tales como el desabastecimiento de la oferta hídrica disponible, esencial para mantener y conservar los ecosistemas fluviales y las necesidades de los usuarios (IDEAM, 2014). Por otro lado, se cuenta también como impacto la reducción del caudal ambiental, el cual, según el MADS (2010), es el caudal hídrico mínimo necesario para la supervivencia de los ecosistemas; además de considerar que "el acceso al agua potable es fundamental para la salud, es uno de los derechos humanos básicos y un componente de las políticas eficaces de protección de la salud" (oMs, 2011).

En relación con la calidad del agua de los ríos de Colombia, se evidencia que esta se ve afectada por la 
cantidad de fuentes contaminantes conectadas con los cuerpos de agua. Al respecto, una de las principales fuentes de contaminación es el vertimiento de los lixiviados generados por los rellenos sanitarios, los cuales no cuentan con la capacidad necesaria para tratar la cantidad generada de dichos componentes. Por consiguiente, para determinar la calidad del agua y el cumplimiento con los límites máximos permisibles en sus componentes, impuestos por la ley, es necesario realizar un diagnóstico del tratamiento previo realizado al efluente. Para ello, se tienen en cuenta factores como el caudal tratado, el tipo y la configuración del tren de tratamiento, su localización y la tecnología que utiliza para su funcionamiento. Lo anterior tiene como objetivo llevar a cabo un análisis inicial de las plantas de tratamiento de lixiviados (PTL) que poseen la mayoría de los RESA.

A partir de lo anterior, resulta necesario identificar los factores que influyen en el funcionamiento de las PTL. Se puede inferir que la variabilidad climática es uno de estos factores. Parámetros como temperatura, altura, presión atmosférica, evapotranspiración y precipitación influyen en el proceso físico, químico o biológico que realizan las plantas, puesto que contribuyen a incrementar la cantidad del lixiviado producido.

Como consecuencia de la descarga del lixiviado sin tratamiento, se evidencia impacto por contaminación de los cuerpos hídricos receptores, tanto superficiales como subterráneos (ríos, lagos, quebradas secas), una de las problemáticas actuales que mayores impactos negativos genera a escala global, amenazando la sostenibilidad del recurso hídrico y poniendo en riesgo la salud de la población. Teniendo en cuenta esta problemática, se hace necesario realizar un análisis comparativo del lixiviado generado en los principales RESA en Colombia, tal como pretende esta investigación.

\section{MATERIALES Y MÉTODOS}

\section{Recopilación de información preliminar}

\section{Rellenos sanitarios en Colombia}

Colombia es un país con una superficie total de $2.070 .408 \mathrm{~km}^{2}$, distribuidos en un área continental de $1.141 .748 \mathrm{~km}^{2}$ y un área marítima de $928.660 \mathrm{~km}^{2}$ (IGAC, 2018). En términos de cantidad de agua que fluye por unidad de área en la nación, el país cuenta con el doble del rendimiento promedio de Latinoamérica, estimado en $21 \mathrm{l} / \mathrm{s}-\mathrm{km}^{2}$ (IDEAM, 2014). Colombia se encuentra dividida en 5 regiones naturales y en 32 departamentos, en el ámbito administrativo. En estos 32 departamentos se dispone aproximadamente de 11,6 toneladas de residuos sólidos (RS) (MAVDT, 2016), los cuales son producidos diariamente por 41.468 .384 habitantes (DANE, 2005).

De acuerdo con información de la Superintendencia de Servicios Públicos Domiciliarios (Superservicios), el país cuenta con 144 rellenos sanitarios autorizados para la disposición de RS. La figura 1 ilustra la ubicación geográfica de RESA en Colombia (Superservicios, 2017), los cuales se encuentran agrupados en determinadas regiones, por lo que, según la Superservicios, algunas zonas del país carecen de este servicio. Teniendo en cuenta lo anterior, en la figura 2 se presenta el porcentaje de RESA en Colombia por regiones naturales; información recopilada a partir de datos recuperados de la Superservicios (2017). Los RESA en Colombia se encuentran ubicados principalmente en la región Andina (66,9\%), seguida de la región Caribe $(11,5 \%)$, Orinoquía $(8,10 \%)$, Pacífica $(8,10 \%)$ y Amazonía (4,7\%). Por su parte, la figura 3 da cuenta de la cantidad de RS generados en cada una de estas regiones del país.

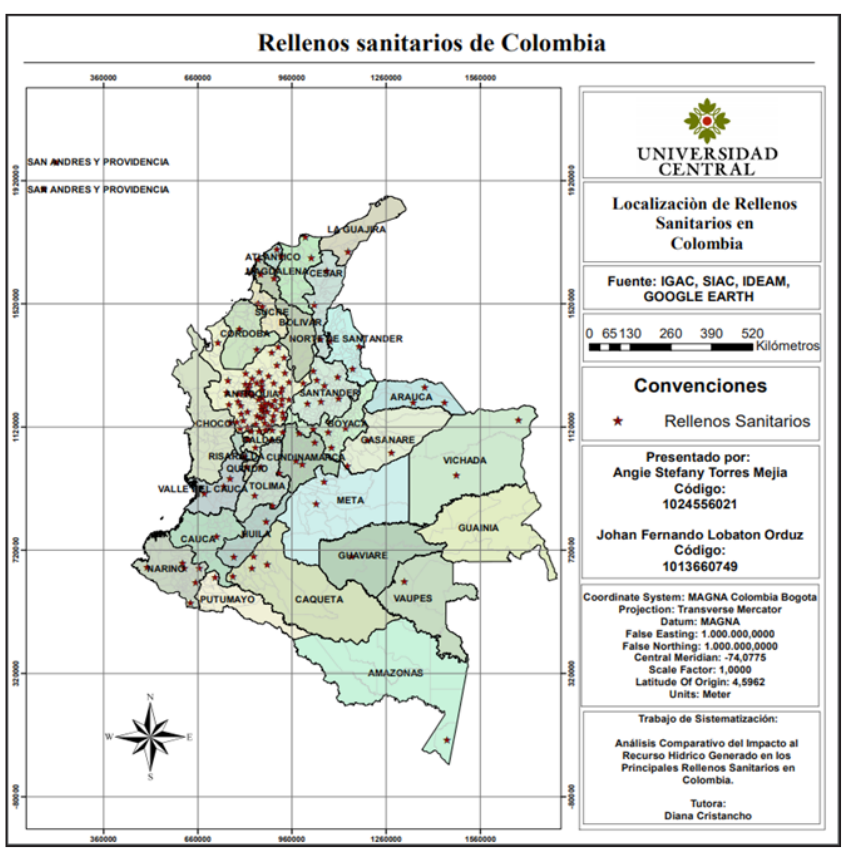

Figura 1. Ubicación geográfica de RESA en Colombia Fuente: autores con información de IGAC, SIAC, IDEAM y Google EARTH. 


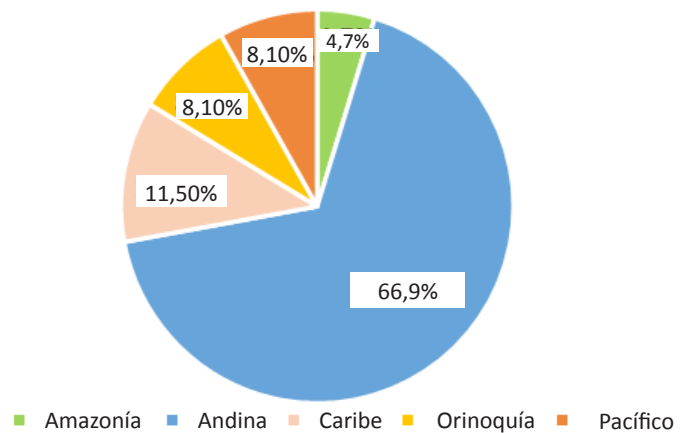

Figura 2. Distribución de RESA por región natural de Colombia Fuente: elaboración propia.

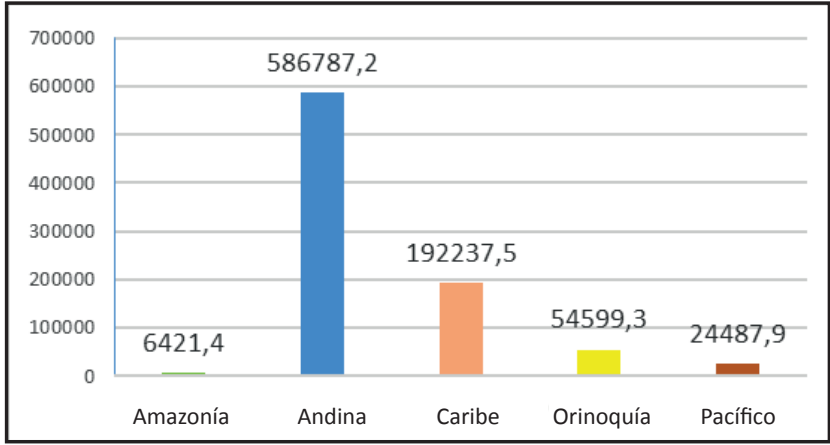

Figura 3. Volumen de RS generados en las regiones naturales de Colombia (toneladas)

Fuente: elaboración propia.

\section{Generación de lixiviados en los RESA de Colombia}

Los lixiviados contienen altas concentraciones de contaminantes orgánicos e inorgánicos, dentro de los que se cuentan ácidos húmicos, nutrientes y metales pesados (MP) como zinc, arsénico, cadmio, níquel cobre, plomo, aluminio, estaño, selenio y mercurio, entre otros (Cristancho-Montenegro, 2013), además de sales inorgánicas y agentes infecciosos (Hernández-Berriel et al., Lugo, 2012). No obstante, las características fisicoquímicas de estos residuos líquidos varían de un lugar a otro, lo que hace necesario llevar a cabo estudios para cada caso particular (Álvarez-Contreras \& Suárez-Gálvez, 2006). La generación de lixiviados y una mala operación en los RESA conducen a la emisión de olores desagradables y gases contaminantes, en especial metano; por ende la contaminación al recurso hídrico por efecto de este vertimiento y un manejo deficiente de la cobertura de los residuos sólidos, la cual, a su vez, aumenta la generación de este líquido residual (Noguera \& Olivero, 2010). La tabla 1 resume los principales parámetros de los lixiviados de un RESA de acuerdo con información suministrada en el trabajo de Giraldo (2001).

Tabla 1. Variables de los parámetros según el tipo de lixiviado

\begin{tabular}{|c|c|c|c|}
\hline Parámetro & $\begin{array}{l}\text { Lixiviado joven } \\
\qquad 5 \text { años }\end{array}$ & $\begin{array}{l}\text { Lixiviados intermedio } \\
\text { 5-10 años }\end{array}$ & $\begin{array}{l}\text { Lixiviado viejo } \\
\text { >10 años }\end{array}$ \\
\hline $\mathrm{PH}$ & 8,26 & 8,5 & 9,58 \\
\hline $\mathrm{DQO}(\mathrm{mg} / 1)$ & 25455 & 6638 & 2197 \\
\hline DBO & 13391 & 1594 & 165 \\
\hline ST & 33796 & 17950 & 9345 \\
\hline $\mathrm{NH}$ & 1090 & 787 & 257 \\
\hline Agentes incrustantes ( $\mathrm{Fe}, \mathrm{Ca}, \mathrm{Mg}$ ) & Muy altos & Medio & ${ }^{\text {Bajos }}$ \\
\hline Detergentes & Muy altos & Medio & Bajos \\
\hline Metales pesados & Muy altos & Medio & Bajos \\
\hline
\end{tabular}

Fuente: autores con información de Giraldo (2001) y Torres et al. (2014).

\section{Depuración y clasificación de la información recolectada}

Gracias a la información recolectada a través de fuentes bibliográficas, licitaciones, trabajos de grado y en- tidades reguladoras de cada departamento fue posible seleccionar los principales RESA de Colombia. Para tal fin, se realizó un filtro en tres pautas: (i) el número de habitantes de los municipios que disponen sus residuos sólidos en RESA, según su licencia ambiental; 
(ii) la cantidad de toneladas mensuales recibidas por cada RESA; y (iii) el caudal de lixiviado generado. Teniendo en cuenta que el caudal oscila por efecto de la incidencia de factores climáticos, se dio mayor peso a las variables número de habitantes y toneladas generadas, puesto que estas no fluctúan de manera drástica en el tiempo. Esta información se relaciona en las tablas 2, 3 y 4 .
Paso seguido, con base en las variables habitantes y toneladas, las cuales son las de mayor peso (toneladas dispuestas mensualmente y número de habitantes que disponen los residuos), se procedió a seleccionar los RESA más representativos del país, considerando que pueden ser también los que mayor impacto podrían estar generando. Por ende, se continuó realizando la comparación de los tres parámetros: número de habitantes, toneladas y caudal.

Tabla 2. Número de habitantes de Colombia por región

\begin{tabular}{|c|c|c|c|c|c|}
\hline \multirow[t]{2}{*}{ Habitantes (Hab) } & \multicolumn{5}{|c|}{ Número de rellenos sanitarios en las regiones de Colombia } \\
\hline & Amazonía & Pacífico & Orinoquía & Andina & Caribe \\
\hline 500 a 5000 & 1 & 3 & 2 & 8 & 0 \\
\hline 5001 a 10000 & 0 & 2 & 2 & 20 & 0 \\
\hline 10001 a 20000 & 3 & 1 & 1 & 18 & 2 \\
\hline 20001 a 50000 & 1 & 1 & 1 & 26 & 0 \\
\hline 50001 a 100000 & 1 & 0 & 4 & 3 & 2 \\
\hline 100001 a 1000000 & 1 & 3 & 7 & 3 & 16 \\
\hline 1000000 a 7000000 & 0 & 0 & 4 & 0 & 8 \\
\hline
\end{tabular}

Fuente: elaboración propia con información de Municipios Colombia (2019).

Tabla 3. Toneladas de residuos por mes generadas en Colombia por región

\begin{tabular}{|c|c|c|c|c|c|}
\hline \multirow[t]{2}{*}{ Toneladas (Ton/mes) } & \multicolumn{5}{|c|}{ Residuos dispuestos en los RESA en Colombia } \\
\hline & Andina & Pacífica & Orinoquía & Amazonía & Caribe \\
\hline 5 a 100 & 34 & 5 & 3 & 1 & 3 \\
\hline 101 a 200 & 16 & 0 & 1 & 1 & 0 \\
\hline 201 a 500 & 12 & 1 & 3 & 3 & 2 \\
\hline 501 a 1000 & 13 & 0 & 1 & 0 & 0 \\
\hline 1001 a 10000 & 12 & 5 & 2 & 2 & 5 \\
\hline 10001 a 50000 & 0 & 0 & 6 & 2 & 10 \\
\hline 50001 a 200000 & 3 & 0 & 0 & 0 & 0 \\
\hline
\end{tabular}

Fuente: elaboración propia con información de Superservicios (2017).

Con la información en la tabla 4 se puede evidenciar los caudales promedio de lixiviado generado en las regiones naturales en Colombia, los cuales van desde 0,004 hasta $2 \mathrm{l} / \mathrm{s}$. Es pertinente mencionar que dicho caudal puede variar en función de las precipitaciones hídricas y la temperatura, teniendo en cuenta que estas variables pueden modificar las características fisicoquímicas y biológicas del lixiviado (Segovia Aseo, 2013).

\section{Tratamiento de lixiviados en Colombia}

En Colombia se manejan diferentes tipos de tratamientos para los lixiviados con el objetivo de disminuir las concentraciones de sus contaminantes, dar cumplimiento a la normatividad vigente y reducir sus impactos sobre recurso hídrico. Los diferentes tratamientos que se emplean en los RESA de Colombia se reflejan en la figura 4. 
Tabla 4. Caudal de lixiviado generado en las Regiones en Colombia

\begin{tabular}{|c|c|c|c|c|c|}
\hline \multirow{2}{*}{$\mathrm{Q}(\mathrm{l} / \mathrm{s})$} & \multicolumn{5}{|c|}{ Rellenos sanitarios } \\
\hline & Andina & Pacífica & Orinoquía & Amazonía & Caribe \\
\hline 0 a 0,0049 & 40 & 6 & 4 & 1 & 4 \\
\hline 0,005 a 0,009 & 13 & 0 & 2 & 1 & 0 \\
\hline 0,01 a 0,19 & 12 & 1 & 1 & 1 & 3 \\
\hline 0,2 а 0,9 & 13 & 1 & 2 & 0 & 0 \\
\hline 1 a 2 & 11 & 1 & 2 & 1 & 4 \\
\hline 2,1 a 5 & 5 & 0 & 0 & 2 & 4 \\
\hline 5,1 a 7,5 & 1 & 1 & 1 & 1 & 1 \\
\hline 7,6 a 12,5 & 2 & 0 & 0 & 0 & 1 \\
\hline
\end{tabular}

Fuente: elaboración propia con información de Superservicios (2017).

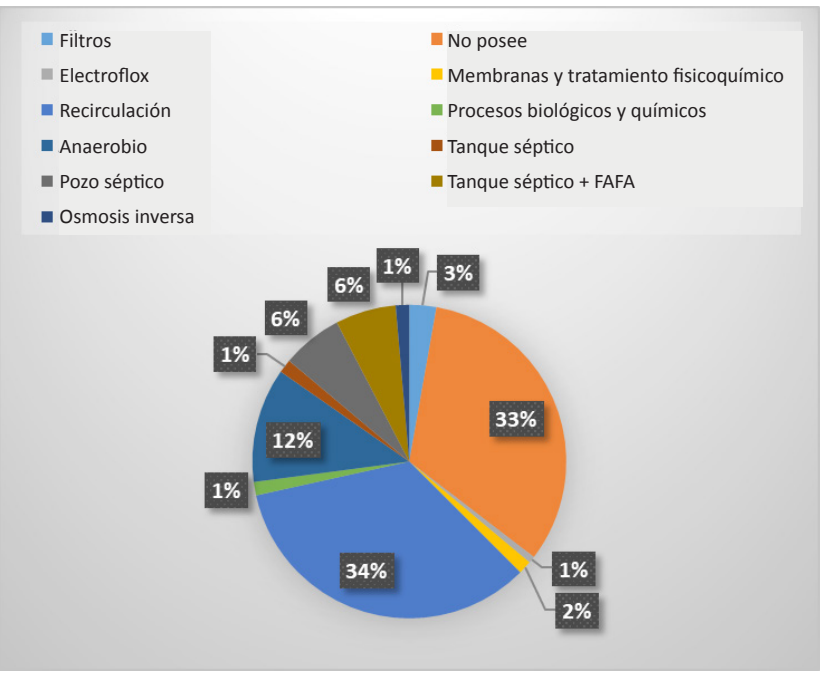

Figura 4. Tipos de tratamientos de lixiviados en los resa de Colombia y su porcentaje de aplicación

Fuente: elaboración propia con información de Superservicios (2017).

\section{DIAGNÓSTICO DE LOS RELLENOS SANITARIOS EN COLOMBIA}

\section{Rellenos sanitarios seleccionados para evaluación}

LOS RESA más representativos del territorio nacional, según se consideró en este estudio, pertenecen a las principales ciudades del país, en las cuales se cuenta con un mayor número de habitantes que disponen de residuos sólidos. Por ende, estos RESA reciben una mayor cantidad de toneladas de residuos por mes y generan un volumen significativo de caudal de lixiviados, el cual se vierte a los recursos hídricos, como se evidencia en la tabla 5.

Tabla 5. Principales RESA en Colombia

\begin{tabular}{|c|c|c|c|c|}
\hline Relleno Sanitario & Ciudad y departamento & Habitantes & Toneladas (t/mes) & Caudal (Q) \\
\hline Doña Juana & Bogotá, Cundinamarca & 6.838 .212 & 188.384 & 8,9 \\
\hline Parque Ambiental La Pradera & Medellín, Antioquia & 3.707 .584 & 79.469 & 3.87 \\
\hline El Guabal & Cali, Valle del Cauca & 3.004 .440 & 70.543 & 0,003 \\
\hline Los Pocitos & Barranquilla, Atlántico & 1.255 .827 & 47.432 & 12 \\
\hline Parque Ambiental Loma de los Cocos & Cartagena, Bolívar & 1.257 .419 & 45.106 & 1 \\
\hline Nuevo Mondoñedo & Mosquera, Cundinamarca & 1.743 .624 & 40.692 & 0,9 \\
\hline El Carrasco & Bucaramanga, Santander & 1.135 .608 & 30.875 & 2,5 \\
\hline Guayabal & Cúcuta, Norte de Santander & 868.122 & 25.257 & 0,7 \\
\hline El Clavo & Palmar de Varela, Atlántico & 832.776 & 23.742 & 1,06 \\
\hline Regional Presidente & San Pedro, Antioquia & 3.355 .652 & 22.341 & 3,72 \\
\hline
\end{tabular}


(Viene página anterior)

\begin{tabular}{ccccc}
\hline Relleno Sanitario & Ciudad y departamento & Habitantes & Toneladas (t/mes) & Caudal (Q) \\
\hline La Esmeralda & Manizales, Caldas & 755.049 & 19.006 & 2,2 \\
\hline La Glorita & Pereira, Risaralda & 1.075 .218 & 18.000 & 16.091 \\
\hline Parque Ecológico Reciclante & Villavicencio, Meta & 603.384 & 15.182 & 12.881 \\
\hline Loma Grande & Montería, Córdoba & 1.447 .883 & 730.67 \\
\hline Los Ángeles & Neiva, Huila & 7306 & 12.300 & 13 \\
\hline Antanas & Pasto, Nariño & 916.306 & 12.043 & 1 \\
\hline Praderas del Magdalena & Girardot, Cundinamarca & 758.288 & &
\end{tabular}

Fuente: elaboración propia con información del DANE (2005).

La mayoría de los RESA a evaluar se encuentran ubicados en la región andina del país debido a que allí se concentran importantes ciudades y la mayor parte de las actividades económicas, producto del acceso a vías. La concentración de los sistemas de recolección de basuras en esta región ocasiona una mayor generación de residuos sólidos en comparación con otras zonas del país, como se evidencia en la figura 5.

\section{Habitantes, toneladas y caudal generado}

Estos RESA cuentan con una cantidad representativa de habitantes que depositan sus residuos en ellos, por ende, generan mayor número de toneladas de residuos sólidos al mes. La figura 6 presenta la cantidad de habitantes que disponen sus RS en IOS RESA evaluados. Estos valores tienen amplias variaciones en algunos casos, en especial los rellenos Doña Juana, La Pradera, Regional Presidente y El Guabal, donde la

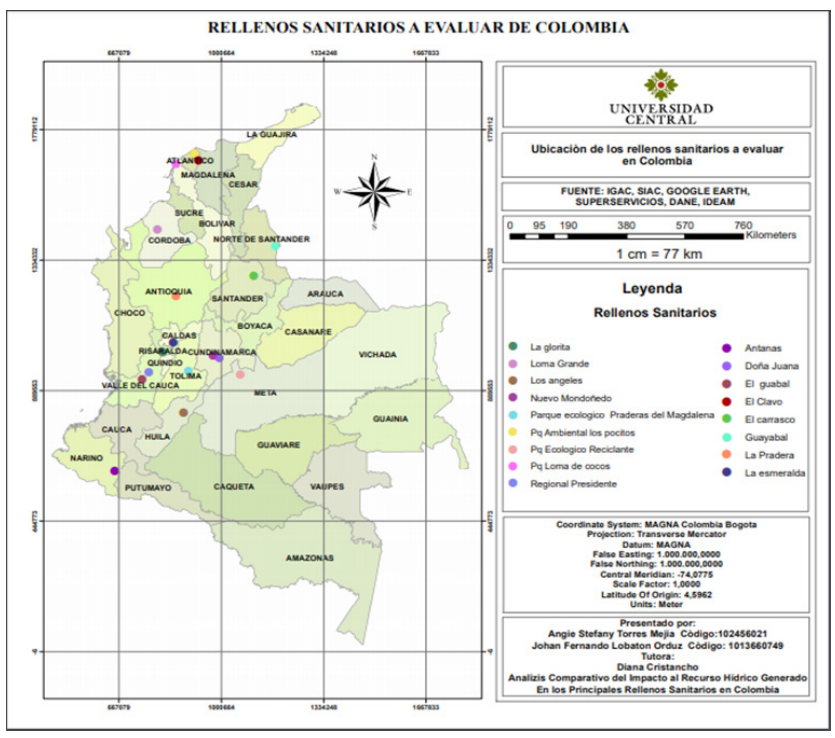

Figura 5. Ubicación de los 17 RESA principales de Colombia Fuente: elaboración propia con información de IGAC, SIAC, IDEAM Y Google EARTH.

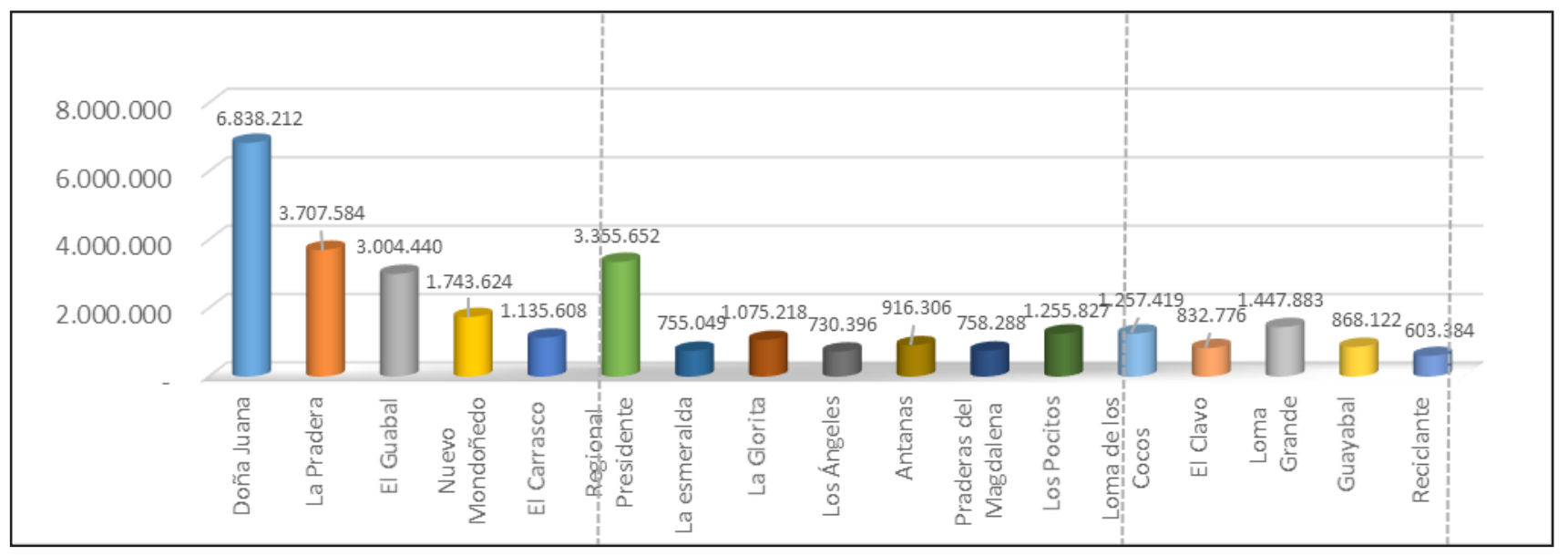

Figura 6. Número de usuarios de los RESA a estudiar

Fuente: elaboración propia con información de Municipios Colombia (2019). 
mayoría de los habitantes de Colombia disponen sus residuos debido a la cercanía de estos RESA con las ciudades con mayores rangos de población.

En la figura 7 se observa que en el RESA Doña Juana se disponen $188.384 \mathrm{t} / \mathrm{mes}$ de RS, un valor significativo en comparación con los demás RESA. Así mismo, los rellenos La Pradera y el Guabal reciben gran cantidad de residuos sólidos al mes, lo que ocasiona la gene- ración de un gran volumen de lixiviados. La figura 8 permite observar el volumen del caudal del lixiviado $(\mathrm{l} / \mathrm{s})$ generado en cada RESA, evidenciando que la mayor generación del líquido se da en los rellenos Los Pocitos, La Glorita y Doña Juana, superando la cifra de $8 \mathrm{l} / \mathrm{s}$; este valor puede variar de acuerdo con las condiciones climáticas y diversos factores que afectan la generación del lixiviado.

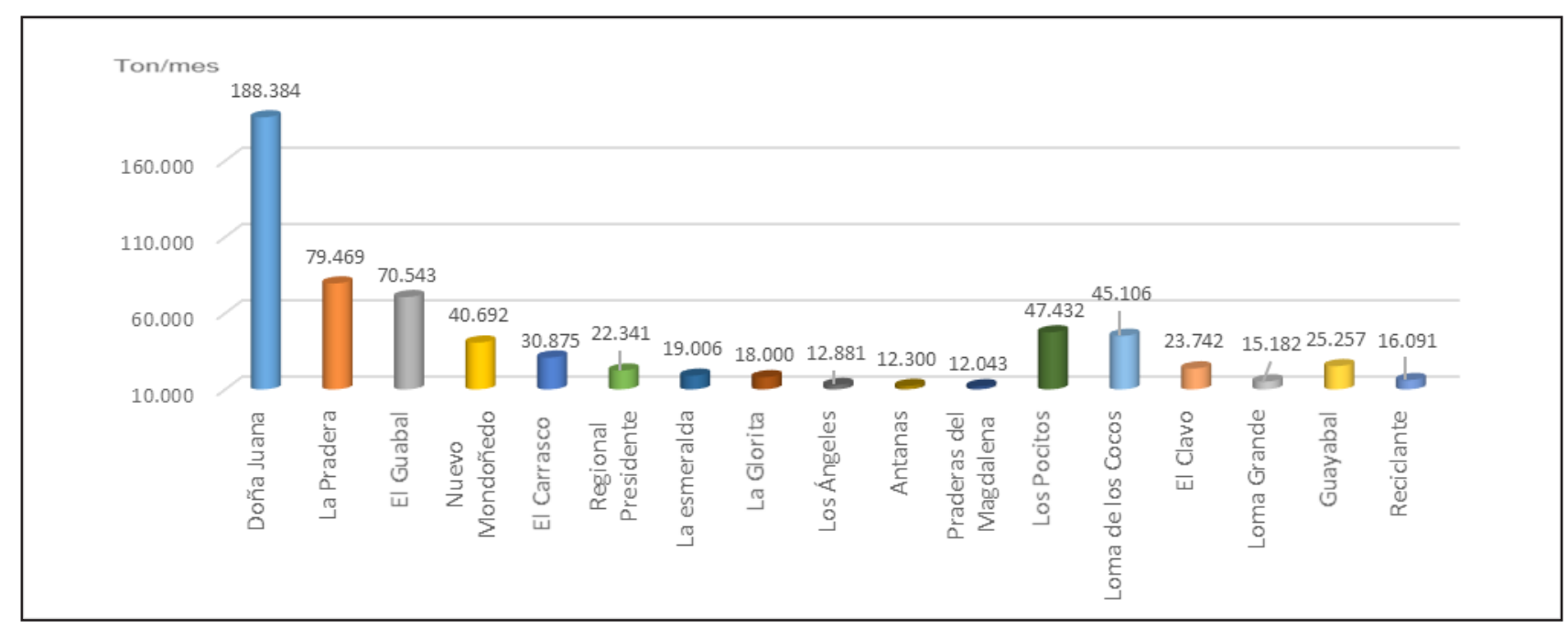

Figura 7. Toneladas de residuos que ingresan a los RESA a evaluar

Fuente: elaboración propia con información de Superservicios (2017).

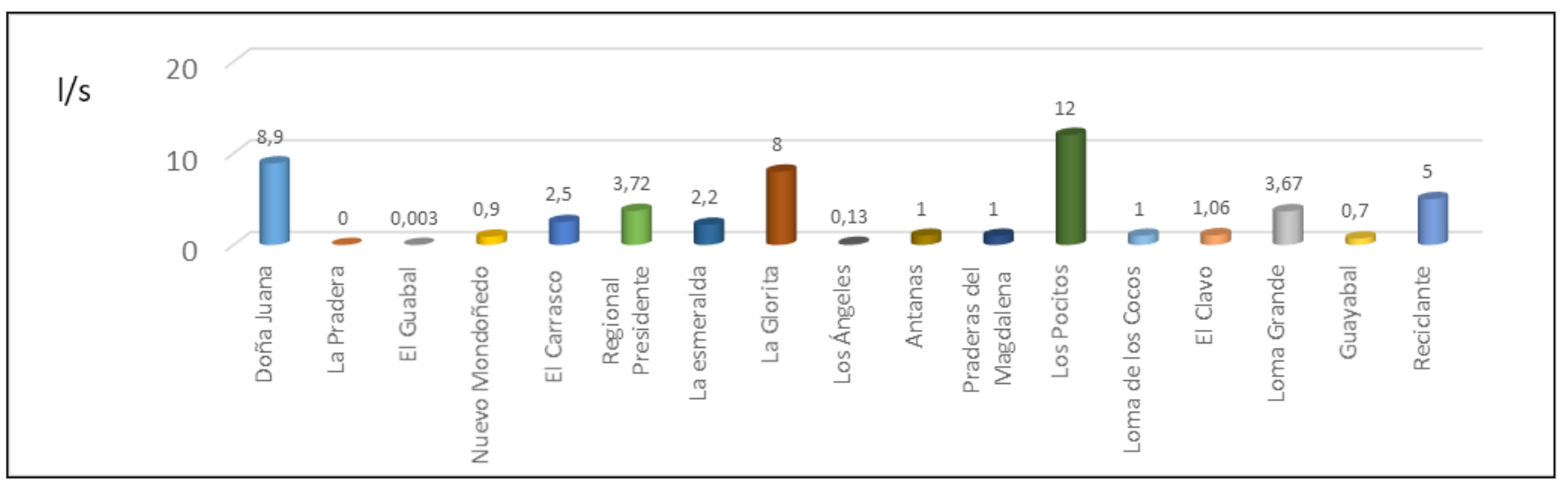

Figura 8. Caudal (Q) de lixiviados de los RESA a evaluar

Fuente: elaboración propia con información de Superservicios (2017).

\section{Tratamiento de lixiviados a evaluar en los 17 RESA seleccionados}

De acuerdo con la información recopilada en este trabajo, en los 17 rellenos seleccionados predominan los tratamientos de tipo anaerobio y la recirculación, como se muestra en la tabla 6 .
Teniendo en cuenta la información en la tabla 6 , se aclara que algunos RESA generan poco caudal de lixiviados por la cantidad de residuos sólidos para disponer, entre otros factores, por lo cual, según la operación del relleno, se utiliza el proceso de recirculación de residuos sólidos en la misma zona de disposición. Esta actividad transforma al RESA en un 
Tabla 6. Tratamiento de lixiviados utilizado en los rellenos a estudiar

\begin{tabular}{|c|c|}
\hline Tratamiento de lixiviado & Rellenos sanitarios \\
\hline \multirow{6}{*}{ Anaerobio } & Doña Juana \\
\hline & Los Pocitos \\
\hline & El Carrasco \\
\hline & La Esmeralda \\
\hline & Parque Ecológico Reciclante \\
\hline & Antanas \\
\hline Electroflox UV & Regional Presidente \\
\hline \multirow{2}{*}{ Osmosis inversa } & Nuevo Mondoñedo \\
\hline & El Guabal \\
\hline No posee & La Glorita \\
\hline $\begin{array}{l}\text { Procesos biológicos y químicos } \\
\text { (aerobio) }\end{array}$ & Parque Ambiental La Pradera \\
\hline \multirow{6}{*}{ Recirculación } & Parque Ambiental Loma de los Cocos \\
\hline & Guayabal \\
\hline & El Clavo \\
\hline & Loma Grande \\
\hline & Los Ángeles \\
\hline & Parque Ecológico Praderas del Magdalena \\
\hline
\end{tabular}

Fuente: elaboración propia.

biorreactor para tratar el efluente, reduciendo significativamente tanto el DBO como los metales pesados. No obstante, este proceso tiene desventajas, tales como la desestabilización del terreno, la acumulación de lixiviados y el aumento de la generación de biogás, para lo cual se tienen que tomar medidas adicionales; por ejemplo, el control del caudal y chimeneas (López-Vega, 2017). Vale la pena mencionar que en algunos rellenos (como Doña Juana) está totalmente prohibido realizar esta actividad debido al evento de deslizamiento que ocurrió en 1997 en el RESA Doña Juana, en la ciudad de Bogotá, y en función de la licencia ambiental que opere. De modo que para este estudio se descartarán los RESA que realizan recirculación, puesto que no generan impacto al recurso hídrico por no realizar vertimiento. A partir de lo anterior, solo se estudiarán los rellenos los Ángeles y
Guayabal debido a que cuentan con laguna de evaporación como pretratamiento adicional.

\section{CLASIFICACIÓN DE RESIDUOS QUE SE DISPONEN EN LOS RESA}

\section{Residuos sólidos}

LOS RESA reciben diariamente residuos sólidos, los cuales se consideran "como cualquier objeto, material, sustancia o elemento, principalmente sólido, resultante del consumo o uso de un bien en actividades domésticas, industriales, comerciales, institucionales o de servicios, que el generador presenta para su recolección por parte de la empresa prestadora del servicio público de aseo" (SIAC, 2013). 


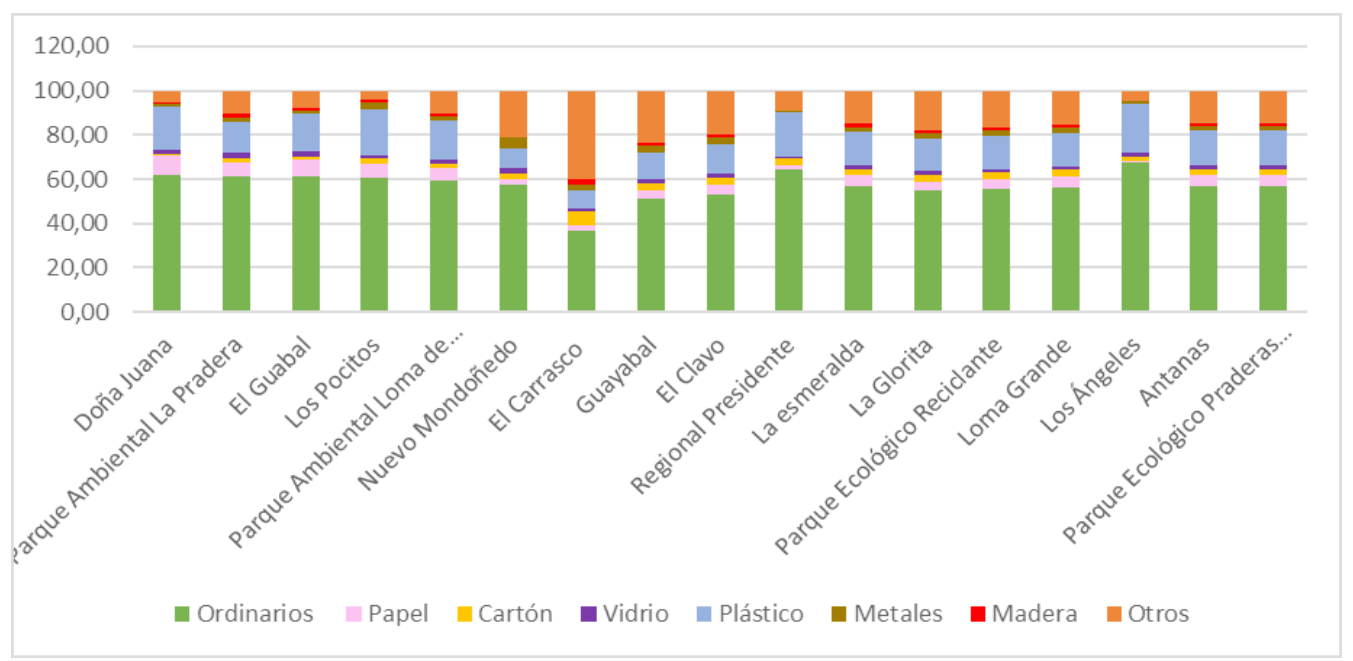

Figura 9. Porcentaje de RS dispuestos en IOS RESA a evaluar Fuente: elaboración propia.

\section{Factores ambientales que influyen en los lixiviados}

\section{Temperatura}

Es primordial tener en cuenta la temperatura en el área de localización del lixiviado, puesto que esta afectará su generación. En la figura 10 se puede apreciar que de los 17 RESA la zona que presenta mayor temperatura es el departamento del Atlántico, donde

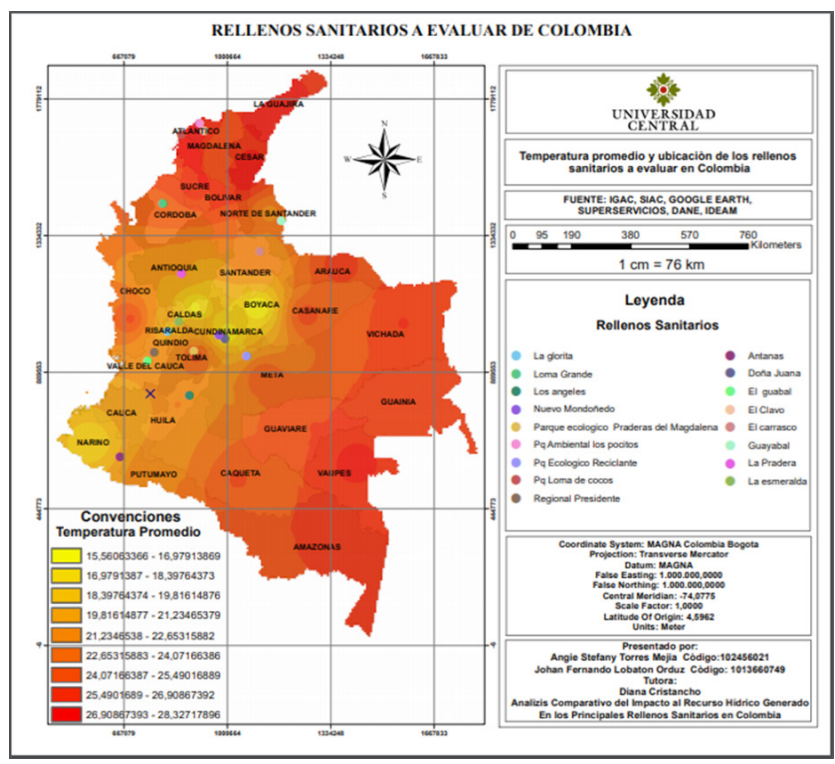

Figura 10. Mapa de temperatura promedio y ubicación de los RESA evaluados Fuente: elaboración propia con información de:IGAC, SIAC, IDEAM Y Google EARTH. se encuentra ubicado el relleno Los Pocitos, y la ciudad de Cartagena, donde se sitúa el Parque Ambiental Loma Grande.

\section{Precipitación}

Debido a que un aumento o una disminución en la precipitación afecta la cantidad de lixiviado generado, se realizó un mapa de este elemento en el territorio nacional y los puntos de localización de los RESA. En la figura 11 se puede evidenciar la precipitación anual total, identificando que el RESA La Pradera se encuentra en una zona que tienen intervalos altos de precipitación. De igual modo, en la parte central del país se observa que la mayoría de los RESA cuenta con niveles similares de precipitación.

\section{Impacto al recurso hídrico por el vertimiento de lixiviado}

El Estudio Nacional del Agua realizado en 2014 dividió el área total del país en cinco regiones hidrográficas. Este trabajo señala que la oferta hídrica que abastece las cabeceras municipales se encuentra vulnerable al desabastecimiento (IDEAM, 2014). Así mismo, permite observar un deterioro en la calidad del recurso debido a vertimientos domésticos e industriales en las zonas aledañas a los principales RESA de Colombia, con lo cual se generan impactos ocasionados por el vertimiento de los lixiviados provenientes de tales vertimientos. En la figura 12 se puede apreciar que los ríos 


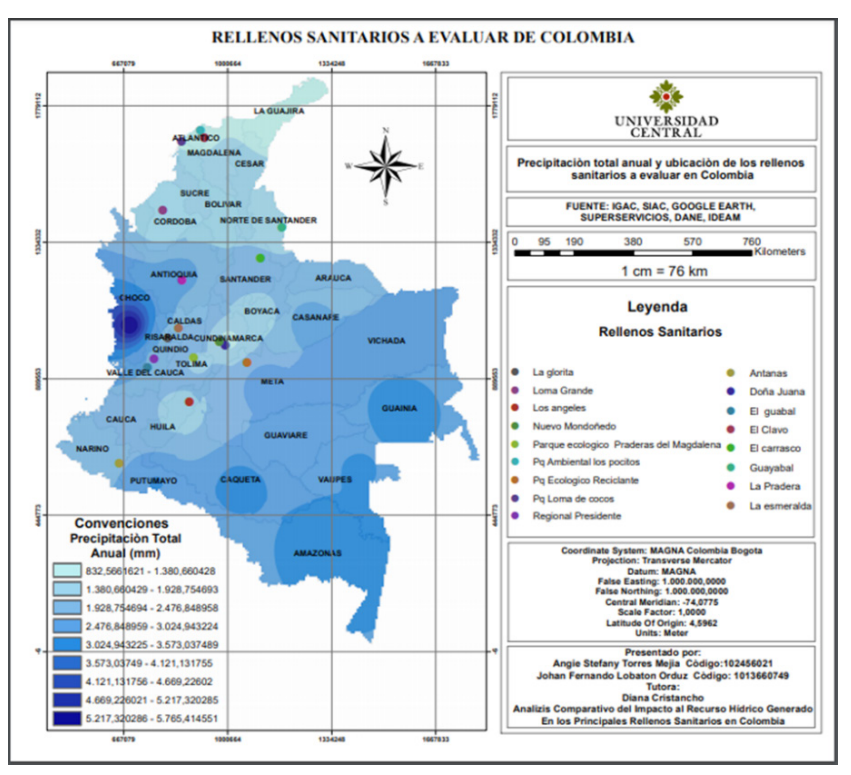

Figura 11. Mapa de precipitación anual y ubicación geográfica de los RESA evaluados

Fuente: elaboración propia con información de IGAC, SIAC, IDEAM Y Google EARTH.

Cauca y Magdalena son los efluentes más afectados por los RESA, situación que deriva de su cercanía con los afluentes de estos cuerpos de agua.

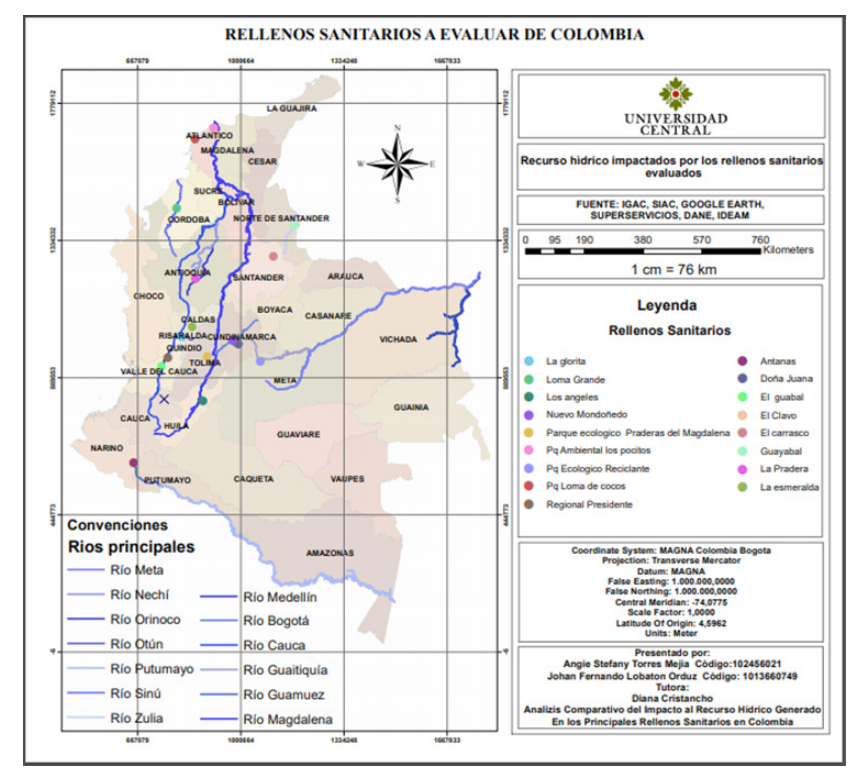

Figura 12. Mapa del recurso hídrico impactado por los RESA evaluados Fuente: autores con información de: IGAC, SIAC, IDEAM Y Google EARTH.

\section{ANÁLISIS DE LOS 17 RESA EVALUADOS}

Con relación a los 17 RESA evaluados, se realizó un análisis para identificar las tecnologías utilizadas en el tratamiento de sus lixiviados, evaluando tanto el cumplimiento a nivel normativo como los impactos a nivel hídrico que generan en la actualidad. Finalmente, se evaluó y planteó la mejor alternativa para el tratamiento de lixiviados en Colombia, buscando así minimizar el impacto potencial de estos residuos al recurso hídrico.

\section{Normatividad}

El lixiviado presenta características que aumentan notablemente su toxicidad y dificultan su tratamiento: DQO, DBO, nitrógenos, sólidos suspendidos, $\mathrm{pH}$ y la presencia abundante de sustancias tóxicas como metales pesados, entre ellos, cadmio, cromo, hierro, plomo y mercurio. A fin de identificar el estado del lixiviado generado en cada RESA evaluado, comparamos los parámetros de su última caracterización con la normatividad aplicable para vertimientos de lixiviados en Colombia, es decir, la Resolución 631 del 17 de marzo de 2015 y la Resolución 1074 de 1997 del DAMA. De esta manera, fue posible determinar el cumplimiento de los límites máximos permisibles.

Con respecto a los principales contaminantes, encontramos los metales pesados, que son, en general, perjudiciales para el ambiente y tóxicos para los seres humanos. Por esta razón, las concentraciones permitidas en el agua de consumo humano por la legislación vigente son muy pequeñas. Los principales metales pesados presentes en la caracterización del lixiviado corresponden a: cadmio (Cd), cobre (Cu), cromo (Cr), níquel $(\mathrm{Ni})$, mercurio $(\mathrm{Hg})$ y plomo $(\mathrm{Pb})$ (Ferré et al., Domingo, 2007). Según el análisis realizado en este trabajo, ninguno de los RESA evaluados cumple con la totalidad de los parámetros exigidos por la normatividad colombiana. Así mismo, en el caso de la Resolución 0631 de 2015, se registra que ningún RESA evaluado cumple con los parámetros establecidos; específicamente, el relleno Regional Presidente supera los límites permisibles de $\mathrm{Pb}, \mathrm{Cu}$ y $\mathrm{Ni}$, mientras que el RESA Carrasco supera los límites de Ni.

Por otra parte, de acuerdo con lo establecido en la Resolución 1074 de 1997, de los RESA evaluados solo El Guabal, Nuevo Mondoñedo y La Esmeralda cumplen 
en su totalidad con los límites máximos permisibles. Sin embargo, nuevamente, el relleno Regional Presidente incumple dicha resolución, reportando niveles altos en metales como $\mathrm{Cd}, \mathrm{Cr}$, $\mathrm{Ni}$ y $\mathrm{Pb}$.

Con respecto al pH, se observa que los RESA evaluados cumplen con las dos normativas aplicables y están dentro de un rango óptimo para el adecuado tratamiento de lixiviados. De esta comparación podemos afirmar que ninguno de los RESA evaluados cumple con el límite máximo permisible en parámetros de gran importancia para el tratamiento del lixiviado, tales como DQO, DBO5, sólidos suspendidos totales y Cd, $\mathrm{Cu}, \mathrm{Cr}$, Ni y Pb. Además, teniendo en cuenta las resoluciones 631 del 2015 y 1074 de 1997, se observa que la segunda norma es un poco menos estricta en su regulación.

\section{Tecnologías}

\section{Eficiencia}

Para determinar la eficiencia de las tecnologías utilizadas para el tratamiento de lixiviados en los RESA evaluados se tienen en cuenta aspectos como los parámetros de su última caracterización y los reportes bibliográficos, tras lo cual se obtienen tres grados de eficiencia: alto medio y bajo.

Los promedios de la caracterización de los 17 RESA evaluados para los parámetros, DQO, DBO, SST, nitrógeno amoniacal $(\mathrm{NH} 3)$ y nitrógeno $(\mathrm{N})$, divididos por el tipo de tratamiento efectuado, permiten obtener una comparación directa de la eficiencia de remoción de estos parámetros para cada uno de los tratamientos implementados. ${ }^{1}$ Esta información permite llegar a las siguientes determinaciones:

- Todos los parámetros tratados por osmosis son menores a $300 \mathrm{mg} / \mathrm{l}$, a excepción del DQo (1.371 $\mathrm{mg} / \mathrm{l})$, los cuales, comparados con los demás, son significativamente inferiores; esto refleja la eficiencia del tratamiento en la remoción de los parámetros.

- Según los datos obtenidos, la recirculación no es efectiva en la remoción de DBO, DQO, SST y N.

1 Los parámetros $\mathrm{NH} 3, \mathrm{~N}$ y SST, que no se observan en los tratamientos electroflox y sin tratamiento, no se tuvieron en cuenta a causa de no encontrar registros.
- Al comparar la eficiencia, se evidencia que los tratamientos aerobio, anaerobio, la recirculación y sin tratamiento, reflejan niveles altos en DQo y SST. Así mismo, estos tratamientos superan los $4.500 \mathrm{mg} / \mathrm{l}$ en DQO.

En la tabla 7 se observan los promedios de la caracterización de los principales metales presentes en los 17 RESA evaluados, divididos por el tipo de tratamiento efectuado. Con el objetivo de comparar su eficiencia, teniendo en cuenta que estos parámetros son difíciles de remover en virtud de su toxicidad, se llega a las siguientes determinaciones:

- El níquel en los tratamientos anaerobios y electroflox están por encima de 0,5 mg/l.

- El tratamiento de electroflox no es eficiente para la remoción de estos metales, de acuerdo con los elevados promedios reportados.

- El tratamiento de osmosis inversa mantiene los metales en un intervalo de 0,001 y 0,101 mg/l, demostrando que tiene la eficiencia necesaria para tratar contaminantes.

- En los tratamientos anaerobios, electroflox y recirculación, el cromo supera el nivel de 0,101 $\mathrm{mg} / \mathrm{l}$. En contraste, en el tratamiento osmosis inversa está muy por debajo de este límite.

En definitiva, escoger el tipo de tecnología para determinado tratamiento depende de las características del lixiviado y de los requerimientos normativos de cada población (Giraldo \& Soler, 2008).

\section{Afectación del lixiviado según la edad}

Los valores obtenidos pueden sufrir variaciones debido al tiempo de apertura del relleno y la cantidad de toneladas depositadas en él. Esta relación es de suma importancia en la definición del sistema de tratamiento a seguir para la depuración de estos líquidos. Así, para lixiviados jóvenes, como primera etapa de tratamiento siempre será recomendable pensar en sistemas biológicos, mientras que para un lixiviado viejo, dada su baja biodegradabilidad, los procesos fisicoquímicos se convierten en la mejor opción (Nájera-Aguilar, 2007). 
Tabla 7. Eficiencia de los tratamientos para el lixiviado

\begin{tabular}{|c|c|c|c|c|c|}
\hline Problemática & Aerobio & Anaerobio & Recirculación & Osmosis & Electrolux \\
\hline DBO & Altos & Bajos & Bajos & Altos & Altos \\
\hline DQO & Bajos & Bajos & Bajos & Medio & Medio \\
\hline Nutrientes & Medio & Bajos & Bajos & Altos & Bajos \\
\hline Metales & Medio & Altos & Medio & Bajos & Bajos \\
\hline Patógenos & Bajos & Medio & Bajos & Alos & Bajos
\end{tabular}

Nota: la tabla se obtuvo con base en la bibliografía relacionada y con los datos de las figuras anteriores, en donde se determinó la eficiencia para la remoción de cada parámetro según este estudio.

Fuente: elaboración propia con información de Salazar-Gámez y Saavedra-Antolínez (2009).

Tabla 8. Vida útil de los rellenos a estudiar

\begin{tabular}{|c|c|c|c|}
\hline Rellenos sanitarios & Inicio & Vita útil & Operación \\
\hline Doña Juana & 1988 & 2022 & 31 \\
\hline Parque Ambiental La Pradera & 2003 & 2027 & 16 \\
\hline El Guabal & 2008 & 2018 & 11 \\
\hline Los Pocitos & 2009 & 2039 & 10 \\
\hline Parque Ambiental Loma de los Cocos & 2006 & 2025 & 13 \\
\hline Nuevo Mondoñedo & 2005 & 2029 & 14 \\
\hline El Carrasco & 1978 & 2020 & 41 \\
\hline Guayabal & 2001 & 2025 & 18 \\
\hline El Clavo & 2009 & 2040 & 10 \\
\hline Regional Presidente & 1998 & 2046 & 21 \\
\hline La Esmeralda & 1999 & 2023 & 20 \\
\hline La Glorita & 2007 & 2025 & 12 \\
\hline Parque Ecológico Reciclante & 2002 & 2040 & 17 \\
\hline Loma Grande & 2010 & 2033 & 9 \\
\hline Los Ángeles & 2003 & 2035 & 16 \\
\hline Antanas & 2001 & 2033 & 18 \\
\hline Parque Ecológico Praderas del Magdalena & 2005 & 2025 & 14 \\
\hline
\end{tabular}

Fuente: elaboración propia.

A partir de los datos en la tabla 8, se puede observar que los RESA El Guabal y El Carrasco están próximos al final de su vida útil para la disposición final de residuos en la zona licenciada. De igual manera, se puede evidenciar que los RESA evaluados tienen un tiempo de operación mayor a 10 años, lo que facilita el tratamiento de sus lixiviados gracias a que las concentraciones de contaminantes han disminuido durante este período.
Influencia en el lixiviado de los 17 RESA por los factores ambientales

\section{Temperatura}

La temperatura del área de ubicación de cada RESA es primordial debido a que a mayor temperatura será más rápida la degradación de la materia orgánica, lo 
que produce un caudal superior de lixiviados. Como se observa en la figura 10, únicamente IOS RESA Los Pocitos, Regional Presidente y Loma Grande se encuentran ubicados en zonas de temperaturas superiores a $25^{\circ} \mathrm{C}$. Los demás RESA se encuentran en zonas tropicales donde la temperatura promedio es de $20{ }^{\circ} \mathrm{C}$, lo que facilita el tratamiento, teniendo en cuenta que esta temperatura es favorable para el adecuado desarrollo de los procesos anaerobios (Barba et al., 2010).

\section{Precipitación}

Las variaciones en el caudal del lixiviado a tratar están asociadas con la cantidad de lluvia. En este caso particular, observamos que los RESA evaluados se encuentran ubicados en zonas de precipitación de 1.500 a $2.000 \mathrm{~mm}$ anuales (rango medio-bajo), lo que beneficia el tratamiento de los RESA debido a que si estos cuentan con un recubrimiento diario tendrán un caudal casi fijo, sin tantas oscilaciones.

\section{Impactos al recurso hídrico}

El agua es de vital importancia para la existencia de la vida en el planeta. Al mismo tiempo, el recurso hí- drico tiene grandes repercusiones en las industrias, el desarrollo económico, la seguridad energética y el transporte. Su reducción o la pérdida de su calidad podrían generar graves dificultades en términos económicos, sociales, políticos, ambientales y de salud pública (Otálora-Gómez et al., 2011). Por tal motivo, en el presente trabajo se reseña el impacto ambiental generado como consecuencia del tratamiento de lixiviados provenientes de RESA que son vertidos en las fuentes hídricas.

\section{Fuentes hídricas afectadas}

Usualmente se considera el tipo y el nivel de tratamiento alcanzado al momento de verter el efluente del sistema de tratamiento de lixiviados en los cuerpos de agua, tanto subterránea como superficial, para lo cual es necesario contar con un permiso de vertimiento que condiciona los requisitos y límites máximos permisibles de los parámetros del líquido (MAVDT, 2005). En la tabla 9 se puede observar cuáles de los 17 RESA evaluados cuentan con permiso de vertimiento, cuáles realizan vertimiento y cuál es su principal afluente.

Tabla 9. Vertimientos de los RESA evaluados

\begin{tabular}{|c|c|c|c|c|c|c|}
\hline RESA & $\begin{array}{l}\text { Permiso de } \\
\text { vertimiento }\end{array}$ & Vertimiento & Caudal (Q) & Efluente secundario & $\begin{array}{l}\text { Efluente } \\
\text { primario }\end{array}$ & $\begin{array}{c}\text { Fuente hídrica } \\
\text { principal }\end{array}$ \\
\hline Doña Juana & En proceso & Sí & 8,9 & Río Tunjuelo & Río Bogotá & Río Magdalena \\
\hline Parque Ambiental & No & Sí & 3,87 & Río Medellín & Río Nechí & Río Cauca \\
\hline El Guabal & Sí & Sí & 0 & Río Jamundí & Río Cauca & Río Magdalena \\
\hline Los Pocitos & Sí & Sí & 12 & Río Malambo & - & Río Magdalena \\
\hline Nuevo Mondoñedo & No & No & 0,9 & Río Chicamocha & Río Bogotá & Río Magdalena \\
\hline El Carrasco & Sí & Sí & 2,5 & Aguas subterráneas & - & - \\
\hline Guayabal & No & No & 0,7 & - & - & Río Zulia \\
\hline Regional Presidente & Sí & No & 3,7 & - & - & Río Cauca \\
\hline La Esmeralda & Sí & Sí & 2,2 & Quebrada Aguas Frías & - & Río Cauca \\
\hline La Glorita & Sí & Sí & 8 & Quebrada La Suecia & Río Otún & Río Cauca \\
\hline Parque Ecológico Reciclante & Sí & Sí & 5 & Río Guataquía & Río Meta & Río Orinoco \\
\hline Los Ángeles & No & No & 0,1 & - & - & Río Magdalena \\
\hline Antanas & Sí & Sí & 1 & Río Guamúez & Río Putumayo & Río Amazonas \\
\hline
\end{tabular}

Fuente: elaboración propia con información de PGIRS municipales. 
Como se evidencia en la tabla 9, los RESA Nuevo Mondoñedo, Guayabal y Los Ángeles no cuentan con permiso de vertimiento. Sin embargo, es de aclarar que no lo requieren debido a que en ellos se realiza la recirculación del lixiviado, evitando que el líquido llegue a las fuentes hídricas. De otro lado, existen casos particulares, como el RESA La Pradera, donde se realiza vertimiento del lixiviado y no se reporta permiso de vertimientos. De acuerdo con la información analizada en esta investigación, los ríos Magdalena, Orinoco, Cauca y Amazonas son los principales afluentes de los lixiviados vertidos por los RESA evaluados; algunas de sus principales características se presentan en la tabla 9.

Tabla 10. Recurso hídrico impactado por los 17 RESA evaluados

\begin{tabular}{|c|c|c|c|c|c|}
\hline Río & $\begin{array}{l}\text { Caudal } \\
\left(\mathrm{m}^{3} / \mathrm{s}\right)\end{array}$ & $\begin{array}{l}\text { Longitud } \\
(\mathrm{km})\end{array}$ & $\begin{array}{l}\text { Superficie } \\
\left(\mathrm{Km}^{2}\right)\end{array}$ & Efluente & Importancia \\
\hline \multirow{4}{*}{ Magdalena } & \multirow{4}{*}{7.200} & \multirow{4}{*}{1.558} & \multirow{4}{*}{226.562} & \multirow{4}{*}{ Mar Caribe } & Río interandino más largo de toda Sudamérica \\
\hline & & & & & Gran vía fluvial y fuente hidroeléctrica \\
\hline & & & & & Patrón principal de la economía del país \\
\hline & & & & & Práctica de pesca \\
\hline \multirow[b]{2}{*}{ Cauca } & \multirow[b]{2}{*}{3000} & \multirow[b]{2}{*}{1350} & \multirow[b]{2}{*}{63.300} & \multirow[b]{2}{*}{$\begin{array}{l}\text { Río } \\
\text { Magdalena }\end{array}$} & $1290 \mathrm{~km}$. son navegables \\
\hline & & & & & $\begin{array}{l}\text { Utilizado para diversas actividades productivas: } \\
\text { agricultura, explotación minera, y generación de } \\
\text { electricidad }\end{array}$ \\
\hline \multirow{4}{*}{ Orinoco } & \multirow{4}{*}{33000} & \multirow{4}{*}{2.140} & \multirow{4}{*}{345.520} & \multirow{4}{*}{ Río Guaviare } & Es el cuarto río sudamericano más largo \\
\hline & & & & & Hábitat de gran cantidad de especies \\
\hline & & & & & $\begin{array}{c}\text { Tiene la Hidroeléctrica Simón Bolívar, la tercera } \\
\text { más grande del mundo. }\end{array}$ \\
\hline & & & & & Tercer río más caudaloso del mundo \\
\hline \multirow{4}{*}{ Amazonas } & \multirow{4}{*}{180000} & \multirow{4}{*}{6800} & \multirow{4}{*}{7050000} & \multirow{4}{*}{$\begin{array}{l}\text { Océano } \\
\text { Atlántico }\end{array}$} & Es el río más largo del mundo \\
\hline & & & & & Río más caudaloso del mundo \\
\hline & & & & & Riega una vasta región \\
\hline & & & & & Soporta miles de especies de seres vivos \\
\hline
\end{tabular}

Fuente: elaboración propia con información del ENA2014 (IDEAM, 2014).

Como se observa en la figura 12, el Río Magdalena destaca por su importancia en actividades productivas como la agricultura, explotación minera, generación eléctrica y, sobre todo, porque en este cuerpo de agua se vierten 5 de los RESA evaluados en este estudio. La contaminación en las aguas del país afecta a cerca de 17,5 millones de personas que se encuentran ubicadas en las regiones aledañas a los ríos Magdalena y Cauca y el Caribe colombiano, en las cuales se reportan 756.945 toneladas de materia orgánica provenientes de las grandes zonas urbanas del país que son depositadas en los RESA que reciben mayor cantidad de toneladas por mes. Esta situación afecta el Índice de Riesgo de Calidad de Agua (IRCA), el cual determina si el agua es apta para el consumo humano, teniendo en cuenta que estos importantes efluentes son utilizados para sistemas de riego y el consumo doméstico (Puentes, 2017).

A partir de lo anterior, se explica por qué el Río Magdalena es considerado como el río con mayores niveles de contaminación en Colombia, según datos reportados por entes de control, hecho que genera grandes impactos al recurso hídrico nacional, pues el Magdalena es uno de los cuerpos de agua más importantes del país al ser el río interandino más largo del mundo, una de la grandes vías fluviales colombianas, albergar fuentes hidroeléctricas, servir de sustento para el 
consumo humano y la pesca, alojar el $53 \%$ de los embalses del país en sus cuencas alta y media, contener $38 \%$ de los puntos de agua subterránea y concentrar $55,8 \%$ de la demanda hídrica nacional para la agricultura (cuenca Magdalena-Cauca) (SDA, 2018).

\section{Contaminantes que impactan al recurso hídrico}

Existen metales necesarios para la vida en bajas proporciones, tales como el hierro, el manganeso, el cobre y el cinc, entre otros. De igual manera, hay otros metales que no reportan efectos beneficiosos para los seres vivos y que, por el contrario, son tóxicos (aun en pequeñas cantidades), como en el caso del mercurio, el cadmio y el plomo (Izquierdo, 1988). Con base en el porcentaje de incumplimiento de los lixiviados en comparación con la norma, se puede observar los metales que no están dentro de los parámetros estipulados, los cuales se describen a continuación.

\section{Cadmio}

Su exposición puede generar anemia, disfunción renal, cálculos renales, osteoporosis, osteomalacia, trastornos respiratorios, hipertensión, trastornos nerviosos, pérdida de peso y apetito, cáncer de próstata y pulmón. Por otro lado, este elemento no es esencial para plantas y animales. Por tal motivo, la Organización de las Naciones Unidas para la Alimentación y la Agricultura (FAO, en inglés) recomienda un nivel máximo para cadmio en aguas de riego de $10 \mathrm{\mu g} / \mathrm{L}$ (Londoño-Franco et al., 2016).

\section{Cromo}

Es conocido por ocasionar varios problemas sobre la salud humana, tales como reacciones alérgicas, erupciones cutáneas, irritación y sangrado de la nariz y debilitamiento del sistema inmune, entre otros. Adicionalmente, este metal puede generar efectos negativos si las plantas lo absorben, además de ocasionar problemas respiratorios en animales (Arauzo et al., 2003).

\section{Plomo}

Este elemento ocasiona afectaciones directas a diferentes órganos. En el cerebro, afecta el desarrollo y la capacidad mental de los niños. No es vital para las plantas y los animales. Además, es tóxico por ingestión y acumulativo en el cuerpo receptor (Poma, 2008).

\section{MEJOR ALTERNATIVA DE TRATAMIENTO}

Al momento de elegir un tratamiento eficiente y adecuado para el manejo de lixiviados es necesario tener en cuenta características como el tiempo de producción, la efectividad de remoción de DQO y DBO y los factores que afectan la generación del lixiviado. En la tabla 11 se hace una exposición de las principales tecnologías existentes para el tratamiento de lixiviados, señalando sus ventajas y desventajas.

Sintetizando la información presentada en la tabla 11, podemos afirmar que las membranas de osmosis inversa son de alta eficiencia debido a que remueven virus, bacterias, iones divalentes y trabajan hasta presiones de 60 bares en módulos convencionales. Adicionalmente, este tratamiento es efectivo en la disminución de DQO, DBO5 y metales pesados, con una eficiencia de $66,86,5,64$ y $57 \%$ frente a los sistemas anaerobios, recirculación, aerobio y electroflox, respectivamente. Sin embargo, teniendo en cuenta criterios como eficiencia, costos, mantenimiento y operación, la osmosis inversa no se presenta como la mejor alternativa debido a sus altos costos de implementación, operación y mantenimiento y una importante restricción de funcionamiento a RESA de bajos caudales.

Por lo anterior, para el tratamiento de lixiviados se sugiere la instalación de pondajes como sistema de amortiguamiento para todos Ios RESA que tengan un caudal superior a 3,5 l/s y alto contenido orgánico y de contaminantes tóxicos. Este tipo de sistemas pueden adecuarse como sistemas biológicos para que las PTL puedan dar cumplimiento a la norma. Cabe mencionar que este sistema es similar al que actualmente ha implementado el RESA Doña Juana como parte de su proceso de optimización.

De otro lado, se recomienda un tratamiento aerobio como el que maneja el RESA La Pradera, el cual refleja buenos porcentajes de eficiencia en comparación con los tratamientos anaerobio, recirculación y electroflox. Adicionalmente, el tratamiento aerobio reporta ventajas como bajos costos de implementación, operación y mantenimiento, simplicidad en su tecnología, alta eficiencia, baja cantidad de subproductos generados en su proceso y una menor generación de gases efecto invernadero (Bernal \& Meneses, 2017). 
Tabla 11. Ventajas y desventajas de los tratamientos de lixiviados

\begin{tabular}{|c|c|c|}
\hline Tratamiento & Ventajas & Desventajas \\
\hline $\begin{array}{l}\text { Recirculación de } \\
\text { lixiviados }\end{array}$ & $\begin{array}{c}\text { Aumento en las tasas de producción } \\
\text { de biogas en el RESA } \\
\text { Menores costos }\end{array}$ & $\begin{array}{l}\text { Aumentos significativos de las presiones internas de los fluidos, gas es y } \\
\text { líquidos, que comprometan la estabilidad de los taludes. } \\
\qquad \begin{array}{c}\text { Inseguridad geotécnica } \\
\text { Únicamente tratamiento primario } \\
\text { Acumulación de líquidos y gases } \\
\text { Únicamente para rellenos pequeños }\end{array}\end{array}$ \\
\hline $\begin{array}{l}\text { Evaporación de } \\
\text { lixiviados }\end{array}$ & $\begin{array}{l}\text { Simplicidad en su tecnología } \\
\text { Eliminación del gas Metano } \\
\text { Costos bajos } \\
\text { Aprovechamiento del gas }\end{array}$ & $\begin{array}{l}\text { Arrastre de covs } \\
\text { Incrustamiento de precipitados en el sistema } \\
\text { Formación de espumas por la turbulencia generada en el proceso de } \\
\text { evaporación }\end{array}$ \\
\hline $\begin{array}{l}\text { Tratamiento } \\
\text { conjunto con las } \\
\text { aguas residuales }\end{array}$ & $\begin{array}{l}\text { Tratamiento conjunto con agua } \\
\text { residual }\end{array}$ & $\begin{array}{c}\text { Dificultad para controlar las concentraciones de componentes orgánicos e } \\
\text { inorgánicos } \\
\text { Corrosión } \\
\text { Reducción de sedimentaldiad del lodo } \\
\text { Producción de lodo con alta concentración de metales puede inhibir la } \\
\text { actividad biológica del lodo }\end{array}$ \\
\hline $\begin{array}{l}\text { Biológico } \\
\text { Aerobio }\end{array}$ & $\begin{array}{l}\text { Pos tratameintos de sistemas } \\
\text { anaeróbicos }\end{array}$ & $\begin{array}{c}\text { Costos altos } \\
\text { Genera espumas } \\
\text { Alta generación de lodos } \\
\text { Altas variaciones en las cargas hidraúlicas y orgánicas } \\
\text { Requieren tanques de ecualizaión de caudales como parte del tratamiento }\end{array}$ \\
\hline $\begin{array}{l}\text { Biológico } \\
\text { Anaerobio }\end{array}$ & $\begin{array}{l}\text { Costos bajos-alta eficiencia } \\
\text { Simplicidad en su tecnología } \\
\text { Menor cantidad de lodos generados }\end{array}$ & $\begin{array}{l}\text { Acumulación de materia orgánica } \\
\text { Pretratamiento (aerobio) }\end{array}$ \\
\hline $\begin{array}{l}\text { Sistemas de } \\
\text { membranas }\end{array}$ & $\begin{array}{l}\text { Disminución del volumen de tanque } \\
\text { del reactor biológico } \\
\text { Excelentes rendimientos de esta } \\
\text { tecnología para la remoción de la } \\
\text { mayoría de los contaminantes } \\
\text { DBo relativamente bajas } \\
\text { Suprimir las necesidades de } \\
\text { oxígeno y mantener una presión de } \\
\text { operación constante en el proceso } \\
\text { La separación entre biomasa y } \\
\text { líquido depurado } \\
\text { Los lodos concentrados retenidos se } \\
\text { recirculan continuamente al reactor, } \\
\text { disponiéndose en él de toda la } \\
\text { biomasa }\end{array}$ & $\begin{array}{l}\text { Aumentos significativos en la cantidad de biomasa que se tiene dentro de } \\
\qquad \begin{array}{l}\text { los reactores } \\
\text { Costos altos }\end{array} \\
\text { Disminuciones en el flujo a través de la membrana por procesos de } \\
\text { taponamiento } \\
\text { Mantenimeinto de este tipo de sistemas } \\
\text { Módulos de membranas son más complicados de operar y mantener que un } \\
\text { sedimentador }\end{array}$ \\
\hline $\begin{array}{l}\text { Tratamientos } \\
\text { Físicoquímicos }\end{array}$ & $\begin{array}{l}\text { Eliminación del color, contenidos } \\
\text { en sólidos en suspensión, amonio } \\
\text { y eliminación de algunos cationes } \\
\text { pesados }\end{array}$ & No se obtienen buenos resultados en la eliminación de materia orgánica \\
\hline $\begin{array}{l}\text { Sistemas } \\
\text { naturales }\end{array}$ & $\begin{array}{l}\text { Bajos costos } \\
\text { Tratamiento primario y terciario } \\
\text { Eficiencia en remoción de mo } \\
\text { Baja generación de espumas }\end{array}$ & Costo alto del terreno \\
\hline
\end{tabular}

Fuente: elaboración propia (2019). 


\section{CONCLUSIONES}

Existen 144 rellenos sanitarios en Colombia, los cuales se encuentran ubicados principalmente en la región Andina (66,9\%), seguida de la región Caribe (11,5\%), la Orinoquía (8, $10 \%)$, la Pacífica $(8,10 \%$ ) y la Amazonía (4,7\%). Para este estudio se seleccionaron 17 RESA a partir de parámetros como número de habitantes que disponen sus RS, cantidad de toneladas recibidas y caudal de lixiviado generado. Se descartaron aqueIlos RESA que realizan recirculación, obteniendo como objeto de estudio un total de 11 RESA: Doña Juana, La Pradera, El Guabal, Los Pocitos, El Carrasco, Regional Presidente, La Glorita, Parque Ecológico Reciclante, Antanas, La esmeralda y Nuevo Mondoñedo.

Se identifica que los RESA objeto de estudio realizan vertimientos al recurso hídrico, impactando cuerpos de agua de gran importancia como los ríos Magdalena, Orinoco, Cauca y Amazonas. Estos vertimientos impactan a los cuerpos hídricos y a todo el ecosistema de las zonas afectadas, generando problemas en la salud humana, la fauna y la flora producto del vertimiento de metales pesados como plomo (8\%), níquel (17\%), cromo (8\%), cadmio (17\%) y cobre (8\%), los cuales contienen grandes niveles de toxicidad y generan bioacumulación en los cuerpos hídricos.

Según la normativa vigente para vertimientos puntuales a cuerpos hídricos y sistemas de alcantarillado público (Resolución 0631 del 2015; Resolución 1074 de 1997 del DAMA), los RESA El Guabal y Nuevo Mondoñedo, ubicados en zonas de temperaturas entre 16 y $21{ }^{\circ} \mathrm{C}$, cuentan con un caudal promedio de lixiviados de $0,5 \mathrm{l} / \mathrm{s}$ y un sistema de osmosis inversa como tratamiento del lixiviado generado, con lo cual dan cumplimiento a los límites máximos permisibles. De acuerdo con lo anterior, las condiciones actuales del tratamiento de los lixiviados de estos dos RESA son adecuadas para garantizar el porcentaje de remoción de los parámetros DQO, DBO, SST y metales pesados $(\mathrm{Cd}, \mathrm{Cr}$, $\mathrm{Cu}, \mathrm{Hg}$ y $\mathrm{Pb}$ ), dado que el sistema de osmosis "filtra" partículas de hasta $0,001 \mu$, los sólidos disueltos en el agua pasan a través de una membrana mediante la aplicación de una fuerza que excede la presión osmótica de los componentes, eliminando el $70 \%$ de la toxicidad existente (Roncancio-Parra, 2015).

Por su parte, los RESA Doña Juana, La Pradera, Los Pocitos, El Carrasco, Regional Presidente, La Glorita, Parque Ecológico Reciclante, Antanas y La Esmeralda, con temperaturas entre 16 y $25^{\circ} \mathrm{C}$, reportan un caudal promedio de 4,89 I/s. Según este estudio y los datos de la caracterización reportados en los PGIRS municipales y de los entes de control, estos RESA se encuentran fuera del rango de los límites máximos permisibles impuestos. Cabe aclarar que los tratamientos de lixiviados que presentan estos RESA son: (i) sistema anaerobio ( 6 de ellos), el cual tiene la desventaja de generar fuertes olores y ser un proceso mucho más lento que el aerobio, además de que no cumple con la remoción de la mayoría de los contaminantes (este es implementado en los RESA más antiguos); (ii) sistema electroflox, que es un sistema de membranas a nivel experimental; y (iii) sistema aerobio, con el cual se obtienen buenos resultados en la eliminación de DQO y eficiencia en la eliminación de metales pesados.

De otro lado, se puede concluir que los RESA El Clavo, Loma de Cocos, Guayabal, Loma Grande, Praderas del Magdalena y Los Ángeles realizan recirculación, por lo tanto, no tienen vertimiento directo a los cuerpos de agua y no generan impacto ambiental. Lo anterior, con base en que su caudal promedio de $0,78 \mathrm{I} / \mathrm{s}$ los convierte en los menores generadores del lixiviados, la cantidad de toneladas de RS que reciben es mucho menor que en otros RESA $(22,36 \mathrm{t} / \mathrm{mes})$ y que sus altas temperaturas $\left(25-28^{\circ} \mathrm{C}\right)$ conllevan a una evaporación acelerada mediante el proceso de aspersión o recirculación

Al momento de elegir la mejor tecnología para obtener un proceso óptimo en el tratamiento de lixiviados es necesario estimar las características de los RESA, las cuales varían según las condiciones climáticas y los tipos de residuos sólidos que ingresan a cada uno. A partir de estas consideraciones, se evaluaron los tratamientos del lixiviado realizados en los RESA más representativos de Colombia, lo que permitió concluir que el sistema de osmosis inversa reporta buenos rendimientos para la remoción de la mayoría de los contaminantes (en especial SST y metales pesados como $\mathrm{Cb}, \mathrm{Pb}, \mathrm{Hg}$ y $\mathrm{Cr}$ ), como reportan los RESA Nuevo Mondoñedo y Guabal, con un cumplimiento de $100 \%$ con relación a la normatividad. A pesar de ello, este tipo de tratamiento tiene las siguientes restricciones: opera de manera óptima con un caudal menor a 0,5 I/s y reporta altos costos de instalación, operación y manteamiento, afectando la relación costo-beneficio, puesto que sus procesos se colmatan muy rápidamente, lo que conlleva a cambios continuos de sus 
filtros, excesos en la generación de los subproductos (biomasa) y la falta de algún tipo de tratamiento de disposición final.

Por último, y teniendo en cuenta lo expuesto anteriormente, se sugiere como mejor alternativa para tratar los lixiviados de los RESA en Colombia que los pondajes deben ser parte fundamental de los sistemas de tratamiento de lixiviados en todos los rellenos, pues estos ayudan a minimizar las carga contaminante, haciendo que esta sea fácilmente asimilada dentro de las PLT, cuyos diseños de caudal son inferiores a lo que realmente se está generando, según lo observado en los rellenos que tiene este tipo de infraestructura. Adicionalmente, se sugiere que algunos de estos pondajes sean adaptados a procesos biológicos con un grado de retención mayor, con lo cual se busca minimizar aún más este tipo de contaminantes. Para finalizar, se sugiere que, de acuerdo con las características del lixiviado de cada RESA, se implemente un proceso de afine como la nano-filtración y/o ultrafiltración, sistemas de membranas que no son tan costosos y contribuyen a remover los demás contaminantes.

Según datos reportados por entes de control, se afirma que el Río Magdalena es el más contaminado del país, lo cual puede ser ocasionado por la conexión directa que tiene con el Río Bogotá o por los vertimientos de los RESA Doña Juana, La Pradera, El Guabal, El Carrasco, La esmeralda, La Glorita y Los Ángeles, que aportan un caudal promedio de $3,8 \mathrm{l} / \mathrm{s}$ de lixiviados con un contenido de 4.126,7 mg/l DQO, $20.716 \mathrm{mg} / \mathrm{l}$ DBO, 7.216,5 mg/l sST, 0,2 mg/l Cd, 0,7 mg/l Cu, 0,88 $\mathrm{mg} / \mathrm{l} \mathrm{Cr}, 0,002 \mathrm{mg} / \mathrm{l} \mathrm{Hg}, 1,93 \mathrm{md} / \mathrm{l} \mathrm{Ni}$ y $0,2 \mathrm{mg} / \mathrm{l} \mathrm{Pb}$, los cuales superan los límites permisibles e impactan directamente al río con estas sustancias tóxicas (Procuraduría General de la Nación, 2013).

Este panorama señala como "extremadamente grave" la contaminación de la principal arteria del país, ya que este cuerpo de agua tiene una influencia directa sobre más de la mitad de los municipios colombianos, es una de las grandes vías fluviales del país, alberga fuentes hidroeléctricas y sirve de sustento para el consumo humano, la pesca y la agricultura. Además, el $53 \%$ de los embalses del país están distribuidos en la cuenca alta y media del río, $38 \%$ de los puntos de agua subterránea se encuentran en sus cuencas y el $55,8 \%$ de la demanda hídrica nacional para la agricultura se concentra en la cuenca Magdalena-Cauca.

\section{REFERENCIAS}

Álvarez-Contreras, A., \& Suárez-Gelvez, J. (2006). Tratamiento biológico del lixiviado generado en el rellenosanitario "El Guayabal" de la ciudad San José de Cúcuta. Ingeniería y Desarrollo, 20, 95-105.

Arauzo, M., Rivera, M., Valladolid, M., Noreña, C., \& Cedenilla, O. (2003). Contaminación por cromo en el agua intersticial, en el agua del cauce y en los sedimentos del río Jarama. Asociación Española de Limnología.

Barba, L. E., Torres, P., Rodríguez Victoria, J. A., Marmolejo, L. F., \& Pizarro, C. A. (2010). Influencia de la incorporación de lixiviados sobre la biodegradabilidad anaerobia de aguas residuales domésticas. Ingeniería e Investigación, 30(1), 7579.

Cristancho-Montenegro, D. L. (2013). Estimación del efecto lixiviado del Relleno Sanitario Doña Juana (tesis de maestría, Universidad Nacional de Colombia). Repositorio Universidad Nacional de Colombia.

Departamento Administrativo Nacional de Estadística [DANE]. (2005). Departamento Administrativo Nacional de Estadística. www.dane.gov.co

Ferré, N., Schuhmacher, M., Llobet, J., \& Domingo, J. (2007). Diseño de un software para evaluar los riesgos de la exposición ambiental a través del agua, suelos y aire. Mapfre Seguridad, 108, 50-58.

Giraldo, E. (2001). Tratamiento de lixiviados de rellenos. Revista de ingeniería Universidad de los Andes, 14, 44-55. https://doi.org/10.16924/riua. v0i14.538

Giraldo, E., \& Soler, N. (2008). Manejo Integrado de Lixiviados y Biogás en Rellenos. ACODAL.

Hernández-Berriel, M., Álvarez, N. O., Vaca, R., Márquez, L., \& Lugo, J. (2012). Determinación de metales pesados en residuos sólidos y lixiviados en biorreactores a diferentes tasas de recirculación. Revista internacional de contaminación ambiental, 18(sup. 1), 77-82. 
Instituto de Hidrología, Meteorología y Estudios Ambientales [IDEAM]. (2014). Estudio Naciona del Agual. IDEAM.

Instituto Geográfico Agustín Codazzi [IGAC]. (2018). Instituto Geográfico Agustín Codazzi. www.igac. gov.co

Izquierdo, A. (1988). Determinación de contaminación con cadmio en el cultivo de cacao (Theobroma cacao L.) y su posible origen en la región de Barlovento Estado Miranda (tesis de maestría, Universidad Central de Venezuela). Repositorio Universidad Central de Venezuela.

Londoño-Franco, L. F., Londoño-Muñoz, P. T., \& Muñoz-García, F. G. (2016). Los riesgos de los metales pesados en la salud humana y animal. Biotecnología en el Sector Agropecuario y Agroindustria, 14(2), 145-153. https://doi. org/10.18684/BSAA(14)145-153

López-Vega, M. E. (2017). La recirculación de lixiviados de rellenos sanitarios en biodigestores a escala de laboratorio. Tecnología Química, 37(3), 433-444.

Ministerio de Ambiente y Desarrollo Sostenible [MADS]. (2002, agosto 6). Decreto 1713. Diario Oficial 44.893.

Ministerio de Ambiente y Desarrollo Sostenible [MADS]. (2010). Política Nacional para la Gestión Integral del Recurso Hídrico. MADS.

Ministerio de Ambiente y Desarrollo Territorial [MAVDT]. (2005, marzo 23). Decreto 0838. Diario Oficial 45862.

Ministerio de Ambiente y Desarrollo Territorial [MAVDT]. (2016). Ministerio de Ambiente y Desarrollo Territorial. http://www.minambiente. gov.co/

Municipios Colombia (2019). Municipios Colombia. https://www.municipios.com.co/

Nájera-Aguilar, H. A. (2007). Lixiviados, ¿Qué son, cómo se clasifican? https://www.unicach.mx/_ ambiental/descargar/Gaceta4/Lixiviados.pdf
Noguera, K., \& Olivero, J. (2010). Los rellenos sanitarios en Latinoamérica: caso colombiano. Revista de la Academia Colombiana de Ciencias Exactas, Físicas y Naturales, 34, 347-356.

Organización Mundial de la Salud [OMs]. (2011). Guías para la calidad del agua de consumo humano (cuarta edición). OMS.

Otálora-Gómez, J. A., Cajiao-Cabrera, A., Ardila-Ariza, M., \& Gómez-Rey, A. (2011). Avance del derecho humano al agua. Defensoría del Pueblo.

Poma, P. A. (2008). Intoxicación por plomo en humanos. Anales de la Facultad de Medicina 69(2), 120-126. https://doi.org/10.15381/anales. v69i2.1155

Procuraduría General de la Nación (2013). Informe de Gestión. Procuraduría General de la Nación.

Puentes, J. (2017, diciembre 13). Estas son las regiones con la mejor y la peor agua de Colombia. Semana Rural. https://semanarural.com/web/articulo/estosson-las-regiones-con-la-mejor-y-la-peor-agua-decolombia/306

Roncancio-Parra, D. (2015). Estudio sobre la aplicación de las técnicas de filtración por membrana a los sistemas de tratamiento de aguas residuales (tesis de pregrado, Universidad La Gran Colombia). Repositorio Institucional Universidad La Gran Colombia.

Salazar-Gámez, L. L., \& Saavedra- Antolínez, I. M. (2009). Tratamiento de lixiviados, casos prácticos en diferentes temperaturas. En // Simposio Iberoamericano de Ingeniería de Residuos. Barranquilla, Colombia, septiembre 24-25.

Semana (2018, enero 27). Río Magdalena: Viaje por las venas de Colombia. Semana. https://www. semana.com/especiales/articulo/viaje-por-lasvenas-de-colombia/554915

Segovia Aseo. (2013, noviembre 26). Segovia aseo E.S.P. http://www.segoviaseo.com/ultimas-noticias/49manejo-de-lixiviados-en-el-relleno-sanitario.html

Sistema de Información Ambiental Colombiano [SIAC]. (2013). Sistema de Información Ambiental Colombiano. http://www.siac.gov.co/ 
Superintendencia de Servicios Públicos Domiciliarios

[Superservicios]. (2017). Informe de Disposición Final de Residuos Sólidos. Superservicios.

Torres, L. P., Barba, H., Ojeda, C., Martínez, J., \& Castaño, Y. (2014). Influencia de la edad de lixiviados sobre su composición físico-química y su potencial de toxicidad. Actualidad \& Divulgación Científica, 17(1), 245-255. https://doi.org/10.31910/rudca. v17.n1.2014.960 